\title{
ISLAM, POLITICA Y PODER EN MARRUECOS
}

\section{ISLAM, POLITICS AND POWER IN MOROCCO}

\author{
Mohamed el Mouden el Mouden \\ Universidad de Cádiz \\ Mohamed.elmouden@uca.es
}

Recibido: julio de 2018

Aceptado: noviembre de 2018

Palabras Clave: Islam político, Monarquía, Política, Poder, Legitimidad, Espacio público.

Keywords : Political Islam, Monarchy, Politics, Power, Legitimacy, Public space.

Resumen: Este texto trata las formas que toma la relación entre la política y la religión en Marruecos a través de las prácticas políticas del poder dominante representado por la monarquía frente a las fuerzas del Islam político que compiten en adquirir la legitimidad de la representación política del Islam en el espacio público. En este artículo se destaca los tipos de las relaciones políticas que se establecen entre la monarquía y el Islam político. Esta relación está sujeta a intereses estratégicos del poder oficial (la monarquía) y a las aspiraciones del Islam político en convertirse en actor legítimo en el juego político desde la religión.

Abstract: This article deals with the forms taken by the relationship between politics and religion in Morocco through the political practices of the dominant power represented by the monarchy against the forces of political Islam. These forces compete in acquiring the legitimacy of the political representation of Islam in the public space. This article highlights the types of political relations that are established between the monarchy and political Islam. This relationship is subject to strategic interests of the official power (the monarchy) and to the aspirations of political Islam to become a legitimate actor in political play from religion.

\section{l. Introducción}

Históricamente el islam constituye el componente principal de la identidad religiosa y cultural de Marruecos. Desde hace más de 14 siglos, con la conquista del país por parte de Uqba Ibn Nafi (683), y cuando Idriss I fundó más tarde la dinastía Idrísida ${ }^{1}$

1. La dinastía fundada por Idrís I, descendiente directo del profeta Mohammad al ser bisnieto del yerno del este, Alí, ha huido debido al fracaso del levantamiento que contra el califa abbasí se había producido en 786, se refugió en el norte del Magreb y se hizo reconocer emir e imán por la qabi- 
(789-974), así como con el advenimiento de otras dinastías a Marruecos, el Islam siempre apareció como religión oficial. Esta religión toma su estructura en el estado y en la sociedad marroquí marcada por la batalla librada entre las instituciones y las fuerzas políticas y religiosas del país por el control de la representación religiosa y del uso político de la religión, así como del uso religioso de la política². Todo ello en busca de un poder políticoreligioso que consolide el predominio. La batalla por dicho predominio político de la religión y religioso de la política es librada por la institución monárquica y las fuerzas del Islam político y toma distintas formas de confrontación, y a veces de alineación cuando hay intereses estratégicos para la monarquía o incluso para las fuerzas del Islam político. La historia contemporánea de Marruecos recalca estas realidades vividas cuando, por ejemplo, la monarquía dio refugio al Salafismo para frenar las fuerzas de izquierda ${ }^{3}$, o para deslegitimar políticamente al Grupo de AL Adl wa AL Ihsan (justicia y caridad) ${ }^{4}$. Por otra parte, da cobijo a otros actores del Islam Político que, para consolidar su legitimidad política, se refugiaron en la monarquía, como ocurrió con AL Adalah wa At- tanmiah (Justicia y desarrollo), el partido político de corte islamista que dirige el gobierno en Marruecos desde la primavera árabe. ${ }^{5}$

lat bereber de los Awarbas. Moueniss,H.(2000) "Ma?āLem Tāryj Al Maĝreb wa al andalus". Dar Ar-Rachād. P .59

2. Hroub, K., (2010) Political Islam: Context versus Ideology, London. Saqi. p.5

3. Salgon, J.M., (2012) Dictionnaire de L'islamisme au Maghreb, L'Harmattan. p.43

4. Ibid.p. 44

5. La primavera árabe ha puesto al poder oficial en Marruecos, y especialmente la monarquía, que goza del poder real en el sistema político, ante un
Sociológicamente esta identidad representada por el Islam se manifiesta por el hecho de que la gran mayoría de la población está constituida por musulmanes, mientras los cristianos y los judíos forman tan sólo el 2 por ciento del total de los habitantes del país. Por tanto, las estructuras culturales, de conocimiento y del pensamiento que produce la sociedad marroquí están basadas sobre fundamentos cognitivos y teóricos, así como conductuales inspirados en esta religión.

Por otra parte, las leyes constitucionales del país siguen vinculando a Marruecos con el Islam como referencia oficial y como marco que dibuja los contornos y los rostros del poder oficial, así como de la oposición política.

El Islam en la vida social y política marroquí cobra distintas formas organizativas, por lo tanto, nos encontramos ante un Islam oficial y un Islam de oposición y entre estos dos extremos, aparecen otras formaciones políticas y sociales que toman posición entre las fuerzas leales al poder oficial (el Islam oficial) y las de la oposición como el Islam político, el Islam social, el Islam predicativo, etc.

Para dibujar una imagen más detallada de la estructura del Islam y la política en Ma-

reto político que lo ha llevado a iniciar unos cambios en la constitución, aunque dichos cambios no alcanzaron el techo reclamado por los activistas de la primavera árabe en Marruecos. Y según analistas del país, la tolerancia por parte de la monarquía al éxito electoral alcanzado por los islamistas de Al adālah wa At-tanmiah (islam político tolerado electoralmente por la monarquía) estaba condicionado por el interés de la institución monárquica y del poder oficial en absorber las reclamaciones del movimiento de 20 febrero, que conducía las protestas en las calles del país durante la primavera árabe, y ofrecer la impresión de que se había producido el cambio político reclamado. 
rruecos, nos detendremos en esta aproximación en cada uno de los componentes, estableciendo los rostros y los caracteres de cada uno. De hecho, podemos preguntar: ¿Cuál es la naturaleza política del Islam? cuáles son los límites de su diversidad y cuáles son sus manifestaciones? ¿Qué tipos de correlación se dan entre sus componentes políticos? ¿Cuál es la naturaleza de los objetivos que mueven las interacciones entre sus diversos elementos?

\section{EL Islam oficial en Marruecos}

Acercarse al Islam oficial en Marruecos requiere una reflexión sobre las fuentes oficiales del Estado como la Constitución, la Institución Monárquica, las instituciones religiosas oficiales y también sobre los discursos acerca del Islam producidos por todas estas fuentes e instituciones. El término "Islam oficial" no significa en absoluto que el Islam de las otras fuerzas sociales de Marruecos circule fuera de los principales fundamentos de la religión islámica, sino que la diferencia radica en la interpretación de la relación del poder político con el Islam mismo que preconiza cada parte. Y por supuesto, la lucha por el poder hace más visibles estas diferencias de matices que no de fundamentos.

A. La Constitución marroquí: La Constitución marroquí, durante sus diversas etapas históricas desde la primera de 1962, hasta la más reciente de 2011 , pasando por las de 1970, 1972 y 1992 determina el Islam como la religión oficial del Estado 6 . Los artículos 6 y 9 de la Constitución indican el tipo de

6. Darif, M. (1996) Al Maghreb fi taqatu3 atturuq, (Marruecos en el cruce de los caminos). Casablanca, Maktabat- al-Najah al Jadida. p. 71 la relación entre el Estado y la religión islámica cuando afirman que: "El Reino de Marruecos, Estado musulmán soberano, cuya lengua oficial es el árabe, constituye una parte del Gran Maghreb Arabe." la religión del Estado, que garantiza a todos el libre ejercicio de la religión» ${ }^{8}$. De estas definiciones constitucionales de la relación del estado marroquí con la religión islámica se desprende la adhesión del país a un sistema cultural, social y político basado sobre esta referencia religiosa ${ }^{9}$.

\section{B. La Monarquía y Emartu-Al-Mou'minin.}

La Constitución marroquí otorga una función vital a la monarquía en el régimen oficial del Estado. Es más, la monarquía es el primer poder en el país y el rey posee un poder que es incluso previo al poder de la Constitución misma, lo que significa que el monarca ostenta la primera competencia para la creación de la Constitución ${ }^{10}$. La Constitución marroquí describe el rey como AmirAl-Mousminin (Comandante de los Fieles), máximo representante de la Nación, símbolo de su unidad. garantía de la permanencia y de la continuidad del Estado, vela por el respeto al Islam y a la Constitución"11, hecho que reconoce el liderazgo religioso del rey.

7. Art. 6 de la Constitución marroquí

8. Art. 9 de la Constitución marroquí

9. Darif. M., (2000) Al Islamiyouna Al Maghāriba, Hisābātu asyāsati fi al amal al islāmi 1969-1999, (los islamistas marroquíes, los intereses de la política en el Mundo islamista., Casablanca. Al Majallah al Maghribiyah li Ilm al Ijtimāe as-siyāsi. p. 27

10. Ibíd., p. 55

11. Art. 19 de la Constitución marroquí 
El término Amir-Al-Mousminin se refiere al léxico político del Islam, y se asocia al concepto esculpido por la legislación islámica como al Jilafatu (Al kalifatu), lo cual indica que la referencia islámica es la que enmarca la formación del poder en Marruecos.

Si este estatuto religioso que otorga la Constitución al monarca como Amir-AlMou'minin consagra la identidad religiosa de Marruecos, el uso de otros términos derivados de las tradiciones islámicas como "mukaddas", sagrado, refuerza la pertenencia del poder oficial a un sistema de poder de carácter religioso. Con la presión de la revolución en Marruecos, la institución monárquica desechó en la nueva Constitución el término "sagrado" y lo sustituyó por el de "inviolable"12.

Otro de los indicativos constitucionales que reflejan el marco religioso de la identidad del Estado marroquí es la referencia de la Constitución misma al Cherifismo de los soberanos, que pertenecen a una dinastía relacionada con el Profeta Mohammad ${ }^{13}$.

La imagen constitucional del soberano se intertextualiza con el modelo del Jalifa (Califa) que surgió en la cultura política islámica y concretamente en su dimensión ideal ${ }^{14}$ esta intertextualidad pretende otorgar a la institución monárquica una legitimidad de poder. En este contexto, el politólogo marroquí Mohamed Tozy afirma que:

12. La Constitución marroquí de 17 junio de 2011 13. Hmimnat, S., (2009) "Al Islam al maghrebi fi al Jitāb al ideologie ar-rasmi” (El Islam Marroquí en el discurso ideológico oficial). En wijahat Nadar. No 39 -año11. pp 8-13

14. Como es el modelo de Abū Bakr Al-Siddīq que fue el sucesor del Profeta Mohammad y por tanto el primer Khalifa del Islam. El segundo Khalifa era Umar ibn al-Jattāb (634 y 644) sucedió a Abu Bakr y gobernó entre 634 y 644.
“La cérémonie d'allégeance est centrale dans la stratégie de la légitimation du system politique marocain. Tous les producteurs de sens attachés au service du royaume s'acharnent à rappeler la filiation de la monarchie avec les premiers gouvernements de I' Islam et s'appliquent à reproduire le rituel politique traditionnel $« 15$

Por otra parte, el régimen político oficial marroquí usa términos con la misma referencia religiosa para la construcción de la imagen constitucional del monarca, consolidando su pertenencia a la cultura política islámica, cuando enmarca la relación entre la monarquía y el pueblo dentro de un concepto político religioso propio del léxico político musulmán, como es Al Baiaá, que indica Según Tozy:

"Bay'a c'est une contractualisation de la relation, dans un cadre d'une Bay'a entre le calife et la collectivité «. ${ }^{16}$

Esta relación que toma forma de contrato, ha sido descrita por Luis Gardet, confirmando que

"En Islam la notion de contrat fait intervenir la volante de rester fidele aux engagements pris, et l'un de ces engagement est, pour l'imam, de servir le bien de la communauté "17.

\section{I Las características del Islam oficial en Marruecos}

Existen distintas características que distinguen el Islam oficial en Marruecos. Algunas están declaradas en la Constitución marroquí, y otras explicitas o implícitas en los discursos políticos y religiosos produ-

15. Tozy, M., (2008) Monarchie et Islam politique au Maroc, Paris. Presses de Science. p.93

16. Ibíd.,p.33

17. Gardet, L.,(1967) L'islam. Religion, et communauté., Paris, Desclée De Brouwer, p. 183 
cidos por las instituciones oficiales del Estado marroquí.

En este contexto, las principales características del Islam oficial marroquí son:

La pertinencia al Madhab (rito) Maleki18: la web del ministro de Habús, asuntos Islámicos ${ }^{19}$, unas de las instituciones oficiales encargadas de gestionar la cuestión religiosa en Marruecos bajo supervisión directa del monarca, define el primer carácter del Islam oficial marroquí, es decir, de la ideología del poder religioso oficial en Marruecos, en "Al Mdhab" (el rito) Maleki" como elemento principal de la identidad religiosa, al afirmar que:

"Le malékisme constitue la pierre angulaire de la culture religieuse marocaine. Des Idrissides jusqu'aux Alaouites, en passant par les Almoravides, les Almohades, les Mérinides et les Saadiens, toutes les dynasties qui se sont succédées sur le trône du Maroc ont consolidé cette école et l'on considérée comme la doctrine officielle de l'état ${ }^{20}$.

18. Existe cuatro Madaheb (ritos) dentro del islam: Al Maleki, Al hanbali, Ash-shafeii, Al- Hanafi. Los Fouqahas (los doctores de la ley islámica) definen el Madhab como la tendencia jurídica adoptada para la interpretación de la Sharia y el método que sigue el mujtahid en la deducción y la argumentación. El Madhab también incluye las ramas (Furu'), además de una escuela. ver cómo está definido por las instituciones religiosas oficiales du Marruecos http://www.habous.gov.ma/fr/index.aspx, acceso: 12/9/2011

19. Es uno de los ministerios de soberanía, es decir aquellos ministerios que no son gobernados por el primer ministro sino por unos ministros nombrados directamente por el rey. Los otros ministerios de soberanía son el de Interior, el de Exteriores y el de Justicia. Véanse http:// www.aujourdhui.ma/imprimer/?rub=actualite $\& \mathrm{r}$ ef $=24056$ acceso: $10 / 10 / 2011$

20. http://www.habous.gov.ma/index.php/ accueil/rubrique-france/academique/islam-aumaroc/article-fr?id=83 acceso: $17 / 10 / 2011$
Por su parte el rey Hassan II, en una de sus opiniones reseñadas en el libro de Eric Laurent: Le génie de la modération: réflexions sur les vérités de l'Islam ${ }^{21}$, indica que la elección del Madahab al Maleki por Marruecos no fue espontánea, sino que fue adoptado por los marroquíes debido a que este Madhab se caracteriza por distintos rasgos que se adecuan a la personalidad marroquí... La adopción de este Mdahab representa el signo de la moderación"22. En el mismo contexto el monarca marroquí considera que: "La tolerancia y la apertura de Marruecos a las culturas que le rodean es gracias a este Mdahab Maleki". ${ }^{23}$

La doctrina Achaari: Es una corriente reconciliadora que tiene como objetivo la moderación y que se sitúa entre la escuela racional Muatazeli24 y la corriente literal salafi ${ }^{25}$. Fue fundado por Abou alHassan AL Ash'ari (270/ 883- 324/935)26 quien quiso establecer un pensamiento y método que reconcilia la razón y el texto coránico ${ }^{27}$. Esta doctrina musulmana fue

21. Laurent, E. (2000) Le génie de la modération réflexions sur les vérités de l'Islam, Paris. Plon. p. 13.

22. Ibíd., p 26

23. Ibíd., p. 28

24. Salīm, S. A. (2000) Al Mutazilah, Tārīj, Akāid, Firaq, Aalām (los muatazilies, Historia, doctrinas, grupos y personajes).institución Nawefal. p 24

25. Hilmi, M., (2005) Manhaju Ulamāe al Hadith wa as- sunnah fi Usul ad-dine (Metodologia de los sabios del Islam en el hadith y as-sunnah en la teología islámica), Lebanon. Dār alkutub al ilmiah. Lebanon., p.15

26. Nacido en una familia árabe del Yemen, jurista musulmán y un gran sabio, Abu al-Hasan al Ash'ari nació en el 270 de la Hégira y murió en 324. Es el fundador de la escuela Ash'ari

27, Sobhi, M. A ., (1985) fi 3ilm_Al_Kalam (En La Teologia islamica), Beirut. Dār an-Nahda al arabia. p 58 
abrazada por el poder oficial y por los marroquíes desde hace más de diez siglos ${ }^{28}$. Los sabios del país y desde luego el poder oficial han considerado esta doctrina, establecida por Al-Hassan Al Ash'ari como una escuela que "ha devuelto las bases de la doctrina sunita salafi a sus orígenes correctos"29. Esta doctrina que fue difundida en Marruecos y en Al Ándalus es definida por el discurso oficial religioso y político marroquí como una doctrina moderada.

La moderación y la tolerancia: Los discursos emitidos por las instituciones oficiales marroquíes, como los discursos del monarca, consideran la moderación y la tolerancia como principales caracteres del Islam oficial marroquí, indicando que la religión oficial del país está abierta y tolera la diversidad religiosa y cultural. En este contexto Hassan II, dentro de su crítica al uso del término de "terrorismo islámico" por parte de los discursos de los medios de comunicación internacionales afirma que "el verdadero Islam no permite aplicar ninguna tendencia política que tienda hacia el extremismo, fanatismo, intolerancia o el terrorismo. Y si eso pasa, pues entonces se debe distinguir entre el Islam como un marco original de civilización, y algunas opciones subjetivas y extremistas de aquellos que ejercen el terrorismo en nombre del Islam. La responsabilidad en este caso es personal y lo mismo podría pasar en cualquier otra religión" ${ }^{30}$. El monarca insiste en el mismo discurso en que "la tolerancia marroquí es una opción original en el fondo histórico de este país" ${ }^{31}$, y cita como ejemplo

28. http://www.arrabita.ma/moubachir/moubachir.aspx?L=37 en árabe .acceso: 12/10/2011

29. Ibíd.

30. Laurent, E. Op. cit,. p. 26

31. Ibíd., 36 "el acuerdo histórico entre el Sultán Merini y el rabino judío Tolidiano en virtud de lo cual Marruecos se encargó de alojar a los judíos y protegerlos de la Inquisición española"32.

Por su parte el politólogo marroquí Salim Hmimnat afirma que el discurso político o religioso oficial del estado marroquí, "se esforzó siempre por unir los valores de moderación y de tolerancia con el Islam oficial del Estado", aunque Salim vuelve en otra ocasión a describir esta tolerancia religiosa del Estado marroquí como "incompleta", señalando que no fue una tolerancia absoluta en cuestiones como las del Partido Comunista marroquí, los Baha i etc. ${ }^{33}$

El Islam oficial es un Islam laico: El islamólogo y politólogo marroquí Mohamed Darif considera en su libro La religión y la política en Marruecos, que el "Islam oficial" en este país es "una traducción real del Islam laico, un Islam que insiste sobre la doctrina y no señala a la Shariia ${ }^{34}$ (la ley islámica)"35. Esto, según Darif, radica en la estructura constitucional del Estado marroquí. Esta conclusión se basa en tres observaciones: 1) La Constitución marroquí habla del Islam como religión y

\section{Ibíd., 37}

33. Hmimnat, S. (2009) "Al Islam al maghrebi fi al Jitāb al ideologie ar-rasmi”, (El Islam Marroquí en el discurso ideológico oficial). En wijahat Nadar. No 39 -año11.p. 8

34. La shariaa como vía o senda del Islam basada sobre el Corán, la tradición del Profeta, el consenso de los sabios, el silogismo, etc. y no como suelen presentarla los medios de comunicación: una ley que se manifiesta en algunos regímenes políticos como Arabia Saudí o en Afganistán, etc. 35. Darif, M. (2000) AL Islāmiuna al Maghāribah, I3tibarātun siasiah fi al feel al Islāmi 1969-1999, Op, cit p. 30 
no como leyes ${ }^{36}$. 2) El legislador marroquí cuando habla del Islam con esta consideración, plantea el término "Islam" como una noción "laica", es decir como un conjunto de prácticas religiosas personales (doctrina) y no como leyes que dirigen el comportamiento del poder político ${ }^{37}$. 3) La Constitución pone la religión al servicio del Estado y por lo tanto es un valor laico, ya que la base principal del laicismo es el valor absoluto del Estado y todos los demás valores están a su servicio ${ }^{38}$

\section{El Islam Predicativo}

La mayoría de los grupos religiosos en Marruecos partieron de la predicación, sin embargo, se refugiaron luego en la acción política que paulatinamente fue dominando todas sus actividades, basándose en la convicción ideológica de que la reforma y el cambio se consiguen solamente a través del poder político. Sin embargo, en Marruecos existen grupos religiosos que limitan sus actividades a la predicación religiosa, y se apartan de la política, creyendo que la predicación individual o colectiva es el método adecuado para una reforma social y espiritual. Es el caso de Jama'at"- tabligh wa-d-a'wa.

A. Jama'at"- tabligh wa-d-a'wa. El origen de esta Jama'at se encuentra en la India donde fue fundada por el Sheik Mohamed Ilias ben Ismail Al Kandahlaoui entre los años 1941 y 194239, y se expandió a través de adeptos pakistaníes a distintos países del mundo islámico. La rama de la Jama'at"- ta-

36. Ibíd., p28

37. Ibíd.,p. 28

38. Ibíd., p.29

39. Tozy, M. Op.cit., p.121 bligh wa-d-a'wa de Marruecos fue fundada en 1964 por el Sheij Mohamed el Hamdaoui. Según Tozy (2008) esta Jama'at

"Incarne une vision très particulière de I Islam, simpliste et focalisée sur une maitrise de geste quotidien". ${ }^{40}$

Por lo tanto, este movimiento dirige su discurso a un público simple como comerciantes, artesanos, etc. No se interesa por las causas políticas, lo que hace que las autoridades del poder oficial acepten sus actividades y les permitan llevar a cabo sus actos de predicación. Con esta posición al Jamaá se enmarca dentro de la misma línea del poder oficial en cuanto a la separación de los grupos y movimientos religiosos de los asuntos políticos ${ }^{41}$.

B. El salafismo tradicional: Hizo su aparición en Marruecos con las actividades religiosas y el pensamiento de Takiy Ad-Dine al Hilali (1893-1987)42. Al Hilali llegó a forjar una escuela "Salafisata Wahabi" cuya herencia fue recogida por diversos grupos del Wahabismo marroquí que no llegaron a conservar un corriente salafi tradicional y coherente, sino que se diversificaron en distintas ramas del salafismo ${ }^{43}$. En este contexto, el islamólogo marroquí Darif afirmaba ${ }^{44}$ que el escenario sala-

\section{Ibid., p. 260}

41. Ver https://bit.ly/2OORUrC en árabe. acceso en $25 / 4 / 2009$

42. El Sabeti, M (1993) As-salafiatu al wahabiah bel maghreb, (el salafismo wahhabi en Marruecos). Rabat. Matbaat al Maāref al Jadidah, P 13

43. Darif.M (2009):El periódico Al Massae 29 de septiembre

44. La islamóloga Malika Zeghal habla solamente de dos formaciones del Salafismo en Marruecos: Salafismo tradicional y Salafismo 
fista marroqui durante los años 90 del pasado siglo estaba formado por cuatro tendencias principales surgidas del salfismo tradicional: una tendencia representada por El Maghraoui un imam y faquih (conocedor de la ley islámica) que fundó una asociación para la enseñanza islámica y supervisó el establecimiento de distintas "escuelas coránicas" con financiación saudí y con el visto bueno del estado marroquí ${ }^{5}$. La segunda tendencia fue representada por los seguidores de Takiy Ad-Dine al Hilali que se negaron a reconocer el liderazgo de El Maghraoui. La tercera rama del salfismo está representada por un grupo de seguidores de El Maghraoui que, estando más tarde en desacuerdo con su "método", decidieron separase de él y fundaron la asociación de "Jamiayatu al Hafed Ibn abdu al Barr"46.

La cuarta rama es aquella que está representada por algunos seguidores de $E$ I Maghraoui, que se alejaron de su tendencia después de acusar a su líder de aliarse con el poder oficial en Arabia Saudí. Estos fueron quienes fundaron el núcleo del fenómeno de Salafismo Yihadista en Marruecos ${ }^{47}$.

Entre estas distintas ramas del salafismo marroquí, queda Yamaiyatu ad -daaoua ila al koraan wa Sunna, "la Asociación para la Predicación del Corán y la Sunna", como la principal fuerza religiosa que representa el salafismo tradicional en Marruecos.

yihadista, véanse ( Zeghal, M, (2005), Les islamistes marocains: le défi à la monarchie, París, La Découverte, Collection Cahiers libres. p. 332)

45. Ibíd., p .332

46. Ibíd., p. 340

47. Ibíd., p .333

\section{EL Islam político}

El Islam político forma parte de las diversas concepciones del Islam que conviven en Marruecos. En este tipo del Islam se mezcla la religión con la política y formando un modelo político activo en la vida política, social y religiosa de la sociedad marroquí. El Islam político por otra parte se convierte en un espacio de lucha entre las fuerzas políticas y el poder oficial y más concretamente la monarquía, que pretende dominar este espacio y convertirlo en exclusivo.

El debate hoy, vinculado con el nacimiento de esta concepción del "Islam político" en Marruecos, toma dos tendencias: 1) considera que el nacimiento del Islam político fue resultado de la experiencia política en Marruecos en la etapa de los setenta y más concretamente del surgimiento de los movimientos islamistas en el Oriente árabe, como los hermanos musulmanes en Egipto, y la consiguiente invasión de sus discursos y su pensamiento en el resto del mundo musulmán, así como de las consecuencias de la llegada de la Revolución Islámica Iraní al poder en este país. Esta primera tendencia estuvo representada por Gilles Kepel ${ }^{48}$ y Bruno Etienne $^{49}$. 2) Es la tendencia representada por los nuevos islamólogos, quienes consideran que el nacimiento de los movimientos islámicos, o "Islam político" es un fenómeno natural que encuentra sus raíces en etapas avanzadas de la historia del Islam ${ }^{50 " ~ y ~ q u e ~ l o ~ q u e ~ e s ~ n u e v o ~ e s ~ " s u ~}$

48. Gilles, K., (2000) Jihad, expansion et déclin de l islamisme, Paris., Gallimard. p .42

49. Etienne, B., (2005) ¿Qué inquieta del Islam?, Barcelona, Edicions Bellaterra. p.126

50. Ben El Mustafá, U., (2008). Al Islamiuna al Maghāribah, (los Islamistas marroquíes) .Casa- 
modelo de movilidad que toma formas modernas adoptando un modelo de organización que corresponde a la evolución de los partidos políticos" 51 .

La primera aparición del islam político en Marruecos después de la independencia, fue con el movimiento de "Ash-shabiba al Islamiya" (La Juventud islámica) que fue creada por Abd el karim Moutie, en el año $1969^{52}$. Este movimiento surgió como consecuencia de interacciones locales y globales, entre ellas: enfrentarse a la expansión Nasirí y a la izquierda marroquí que estaba en los años 70 en su momento fuerte. La aparición de esta formación islamista fue apoyada por el régimen oficial marroquí que estaba amenazado por la izquierda política a nivel local y regional53. La vida oficial de este movimiento islamista no supero los cuatro años, pues en ese momento se vio inmerso en un enfrentamiento con el poder oficial marroquí que decidió prohibir su existencia en el escenario político oficial. Por otra parte, la prohibición de este movimiento coincidió con el nacimiento de nuevos movimientos islamistas, algunos surgidos de Al Shabiba y otras nacidas dentro de nuevas concepciones políticas y religiosas y que toman distancia con el poder oficial de diversas maneras. En este contexto la islamóloga en la universidad de Chicago Malika Zeghal ha dividido el Islam político en Marruecos en tres grupos: (1) Islam político tolerado por el régimen oficial, que es aquel movimiento islamista

blanca. Dar Tubkal. p. 11

51. Ibíd., p .12

52. Darif, M., (1999). Al Islamiyouna Al Maghāriba, Hisābātu asyāsati fi al amal al islāmi. (los islamistas marroquíes, los intereses de la política en el Mundo islamista )., Casa Blanca. Al Majallah al Maghribiyah li Ilm al Ijtimāe assiyāsi. p.14

53. Ibíd., p 20 que pretende, según Darif, controlar la religión a través de la política ${ }^{54}$ y se cristaliza en el escenario político marroquí en dos fuerzas políticas islamistas: una representada dentro del parlamento marroquí, y la segunda es un Islam político que se identifica con el discurso de la izquierda con el slogan de "la democratización del Islam", y está representado por el partido Albadil Al Hadari (La alternativa de la civilización) y Alharakah Min Ayli al Ummah (El movimiento por la Nación). Estas fuerzas del Islam político ejercen sus actividades fuera del Parlamento pero dentro de las condiciones de la política oficial marroquí . (2) Islam político sufí rebelde que niega participar en el ejercicio político oficial. Se trata de un movimiento que no está legalizado y que no acepta la participación política con las condiciones del Estado, sin embargo, su ausencia como actor político legal no limita, en cierta manera, su gran influencia en la vida política. Y como dice la politóloga Malika Zeghal, "esta fuerza representa una fuerte singularidad dentro de los círculos islámicos más allá de las fronteras de Marruecos. Su movimiento se basa en el misticismo y trabaja como una Zawyia"55. (3) Un Islam Jihadista ${ }^{56}$, que es una corriente que aspira a controlar la política a través de la religión, dentro de él se inscribe el movimiento salafi y los jihadistas. ${ }^{57}$

\section{El lslam "Yihadista"}

La corriente Ilamada Islam "Yihadista" abarca diversas formaciones que

54. Darif, M., (2000) AL Islāmiuna al Maghāribah, Hisātun siasiah fi al feel al Islāmi”, Op, cit. p. 102

55. Zeghal, M., (2005), Op. Cit., p. 50

56. Ibid p 53

57. Darif.M., (2000), Op. Cit., p. 102 
pertenecen a distintas referencias religiosas con el denominador común del uso de la violencia para alcanzar algunos objetivos estratégicos, como es el caso de Ash-shabiaba al Islamiya en los años 70 en Marruecos, o para imponer su ideología o sus ideas como el Salafismo Yihadista. Estas tendencias religiosas parten del mismo principio, como ha señalado Daraif: "el control de la política a través de la religión". Las ideas que justifican la acción política de estos movimientos Yihadistas fueron importadas al escenario político y religioso marroquí desde Egipto y Arabia Saudí. Mustafa ben Hamza, uno de los sabios y ulemas más destacados de Marruecos, afirma que "en los años sesenta del siglo pasado distintas corrientes centrales han adoptado un pensamiento que se basa sobre at-takfir (situar musulmanes fuera del Islam por no compartir las mismas interpretaciones) totalitario tanto de sistemas políticos como de individuos y sociedades con sus distintos componentes a base de lecturas no correctas de los textos de Ash-Shariaa (el Corán y los hadices del Profeta)"58. Por otra parte, Mohamed Sahabi, un clérigo musulman de Marruecos señala que "la referencia de algunas fuerzas Yihadistas en Marruecos es Jamaaatu al Yihad de Egipto que mandó a un enviado para difundir las ideas de este grupo y empezar a promoverlo entre los jóvenes marroquíes" 59 .

El mapa de los movimientos denominados yihadistas en Marruecos lo ha dibujado el islamólogo marroquí Mohamed Darif en su obra La religión y la política en Marrue$\cos ^{60}$ y lo limita a los siguientes grupos:

58. Ben Hamza, M., (2017). https://www.hespress. com/orbites/375124.html. Acceso 31 de julio.

59. Lekhlafa, A (2010). https://www.maghress. com/marayapress/1123 acceso 02/agosto/2018

60. Darif.M (2000). Op.cit., p 56
- El movimiento de Ash-shabiaba al Islamiya: después de establecer su ala militar dirigida por Abd El Aziz el Nuamani, se organizó otra ala yihadista en el año 2001, que después de la desintegración del movimiento y la retirada del Nuamani ha tomado como nombre Fasil al Yihad ${ }^{61}$.

- Munadamatu al MojaHidina fi Al Mghreb (Organización de los Muyahidines en Marruecos): fue establecida en 1984 por el Nuamani después de que haya salió de la organización de "Ashshabiba al Islamiya". 62

- Jamaatu At Takfir wa Al Hijra: fue un movimiento que surgió como expansión del movimiento Jamaatu At Takfir wa Al Hijra egipcio, y que tenía también una presencia fuerte en Argelia. Pero Darif considera que este grupo no existe como tal movimiento, aunque aparece como expresión política de pequeños grupos. ${ }^{63}$

- El Salafismo Yihadista: es una rama descendiente del salafismo tradicional, y se caracteriza por el radicalismo, pero se alejó y se separó del mismo ya que este se dedica a la predicación y la educación pacífica y consintió que el régimen de Arabia Saudí permitiera el establecimiento de las bases militares de los norteamericanos en lo que consideran como tierra santa. Entonces estos salafies separatistas decidieron establecer el núcleo del Salafismo Yihadista en Marruecos ${ }^{64}$.

- Jamaatu al hijra wa at takfir: es una secta nacida en los años 80 de manos de algunos individuos del barrio marginado de Sidi Moumen en Casablanca.

61. Ibid., p 113

62. Ibíd., p113

63. Ibíd., p .114

64. Darif.M., (2009) http://cort.as/-7Ycg acceso $17 / 10 / 2017$ 
Encabezada por Mohamed Daouod el Jamli, su líder espiritual, sitúa al régimen y a la sociedad de Marruecos fuera del Islam (takfir) y llama a luchar contra esta sociedad y sus instituciones, aspirando a crear lo que ella denomina "el grupo de los creyentes" 65.

- Jamaat As serat Al moustaqim (El grupo del camino recto): apareció esta organización en 1996 en Casablanca de la mano de Zkaria el Miloudi y aglutina a decenas de miembros y simpatizantes en barrios marginales de Casablanca, Fez, Tánger... Su doctrina está basada sobre attakfir (situar un musulmán fuera del Islam). Algunos de sus miembros fueron acusados por los atentados terroristas del 16 de mayo de 2003 en Casablanca ${ }^{66}$.

- Al Jamaa al Islamiya al maghribia al Moukatila (El Grupo Islámico Combatiente Marroqui): no fue reconocido como grupo yihadista hasta los atentados de 16 de mayo de 2003 en Casablanca, pero sobre todo cuando fueron señalados por las autoridades españolas como el grupo que cometió los atentados terroristas de Madrid. Algunos de las fuentes mediáticos han considerado que este grupo se originó con marroquíes instalados en Afganistán en la época de Ben Laden cuando estaban los talibanes en el poder, y que se formó después de separarse del grupo de Aljamaa al libiya al moukatila (El Grupo Islámico Combatiente libio). El número de marroquíes que estaban en aquel

65. El kablan, I.O. (2003): http://www.diwanalarab.com/spip.php?article7576 en árabe: Acceso: $23 / / 07 / 2010$

66. El Raoui, M. (2003) periódico Asharq Al Awsat. Véanse http://www.aawsat.com/details. asp? article $=172207 \&$ issueno= 8941 en árabe. Acceso: 17/09/2010. momento en Afganistán alcanzaba las doscientas cincuenta personas, siendo algunos de ellos detenidos y enviados a Guantánamo durante la guerra norteamericana en Afganistán, mientras que otros volvieron a Marruecos y allí fueron detenidos ${ }^{67}$.

El análisis de estos grupos se enfrenta a muchas dificultades metodológicas y analíticas, ya que son grupos minoritarios en Marruecos y apenas tienen seguidores, por lo que están rodeados de mucha ambigüedad. Estos grupos no han generado documentos escritos que ayuden a entender el fenómeno, como ha sido el caso de los hermanos muslámenes o de otros grupos islamistas. Los escritos sobre ellos se reducen a investigaciones policiales o periodísticas.

\section{El Islam político social}

El representante en Marruecos del Islam social es Jamaatu Al adl wa al Ihsan (Grupo de Justicia y Caridad), uno de los movimientos islámicos con más peso social y político en Marruecos, que constituye el gran reto para el poder oficial, y más concretamente para la Monarquía. Uno de sus principios es descartar la violencia y no aceptar las condiciones políticas del poder oficial, por lo que tiene prohibida la participación política ${ }^{68}$.

La acción social y religiosa del Jamaatu Al adl wa al Ihsan" se basa en la predicación y la educación. Deriva de su referencia sufí, sus principios filosóficos y de praxis $^{69}$, pero al mismo tiempo aspira

67. Al Massae (2007)- Periódico. 21 de septiembre. 68. Malika Z., (2005) Op. cit., p. 48

69. El fundador de esta Jamaa, Abd As Salam Yassine, fue un seguidor de la escuela sufí marroquí Altarika al budchichiya 
a ejercer la política en oposición a la monarquía, lo que hace que su participación en la vida política marroquí esté condicionada al cambio de su position ante dicha institución.

Fue fundado en el año 1981 por su líder espiritual Abd As -Salam Yassine (1928), con el nombre de Usratu al Jamma, denominación que fue cambiada varias veces a causa del rechazo del poder oficial hasta que en el año 1987, Al Jamaa pasó a llamarse Al adl wa al Ihsan". El cambio frecuente de nombre es signo de la difícil convivencia entre el Estado y el Jamaa, que fue descrito por el politólogo Mohamed Tozy como:

" Une communauté terriblement et de surcroit bien organisée, c'est une communauté ou se mêlent le charismatique et l'activisme politico-religieu ${ }^{70}$ ».

Por otra parte la islamóloga de la universidad de Chicago Malika Zegal considera esta Jamaá como "uno de los grupos más influyentes en Marruecos cuyo número de seguidores superna los treinta mi ${ }^{71}$. A juicio de Zegal, al Jamáa :

"Présente une forte singularité dans les cercles islamistes, qui dépasse les frontières du Maroc. Son mouvement est fondé sur le mysticisme et fonctionne comme une zaouia. II ne reconnaît pas de légitimité à la monarchie marocaine, mais demande dans le même temps à être reconnu comme parti politique". ${ }^{72}$

Al adl wa al Ihsan se deferencia de otras organizaciones islamistas de Marruecos, por su línea política, que fue denominada por sus analistas como una "tercera línea política" que no pertenece ni a la línea re-

70. Tozy. M (2008). Op. cit., pp.185-187.

71. Zeghal. M., (2005). Op. cit., p. 56

72. Ibíd. p 57 volucionaria violenta abrazada por grupos radicales, ni tampoco a grupos islamistas que aceptaron "el apaciguamiento negativo", es decir, la participación política con las condiciones de lo que el grupo mismo llama El Majzén $n^{73}$.

\section{Conclusión}

Lo que caracteriza el conflicto por el control del poder político de la religión entre la monarquía y las fuerzas islámicas políticas en Marruecos es la doble posición que ostenta la Monarquía como poder político y religioso frente a estas fuerzas islamistas.

Esta actitud está condicionada por los intereses más estratégicos de la Monarquía, encarnados en su voluntad de conservar de forma exclusiva la representación del poder religioso y político al mismo tiempo. Es una lucha, por otra parte, de esta institución no solamente para apoderarse de la legitimidad constitucional de dicha representación exclusiva, sino también de la social y la real74. Esta realidad limita el margen representativo de la religión en el espacio público ante las fuerzas políticas

El sistema político de la religión expuesto en este trabajo refleja en cierto modo una estructura de lucha política de todas las fuerzas islamistas, entre sí en ocasiones y frente de la institución monárquica en otras, para obtener una legitimidad representativa de la religión en el Estado marroquí. Esta lucha conduce a crear relaciones de interés impuestas por las circunstancias políticas y estratégicas que vive el Estado. Desde siempre el poder oficial en Marrue-

73. Youssfi, I: Analista del grupo. de al Jamáa, http://www.aljamaa.net/

74. BenElmostafa, U., (2007) Op. cit., p. 118 
cos, representado por la Monarquía, ve en las fuerzas islamistas una amenaza a su legitimidad como representante de la religión y a su poder político, aunque en otros momentos de la historia actual de Marruecos la monarquía marroquí se haya aliado con fuerzas islamistas para desactivar las amenazas políticas de las fuerzas de la izquierda radical, después de sufrir distintos intentos de golpe de Estado militar y para desviar o absorber influencias externas, en una confrontación visible e invisible con estas fuerzas.

En esta confrontación, la institución monárquica a veces recurre al uso de algunas de las fuerzas islamistas en contra de otras, como ha sucedido en ocasiones anteriores cuanto utilizó a los salafistas para frenar a los Hermanos Musulmanes de Marruecos, concretamente Al adl wa Al Ihsan, o como está sucediendo en la actualidad cuando utiliza a los sufíes en contra del salafismo.

Eso significa que el poder político de la religión se constituye como fuente de conflicto y de lucha entre la Monarquía, que establece su legitimidad a base de la religión, y las fuerzas islámicas, que parten de un marco referencial religioso y cuya fuerza política se fundamenta en la religión. En este contexto, la Monarquía se apoya en una utilización de autoridad que consiste en el control de las fuentes de formación de la opinión publica religiosa, que fue descrita por Russell como «la más poderosa». Por este motivo, encontramos que el Estado domina instituciones que pueden impactar y crear la opinión pública religiosa, como el Ministerio de Asuntos Religiosos, que tiene la consideración de ministerio de soberanía, por lo que está en manos de la Monarquía y no del Gobierno, como el Ministerio del Interior y el de Defensa. La creación de instituciones científicas y religiosas leales a la monarquía y que gozan de su apoyo, como Ar-rrabita al Muhammadia, forma una parte del plan del control del discurso religioso y de la interpretación de sus símbolos políticos.

El poder oficial, representado por la Monarquía en este marco, crea medios de control de los espacios donde tienen lugar ritos religiosos, como las mezquitas. $Y$ para mayor control, el Estado marroquí ha colocado dentro de las grandes mezquitas pantallas de televisión para transmitir en estos espacios religiosos un discurso controlado e impedir cualquier posibilidad de filtración de discursos religioso independientes o de otras fuerzas islamistas adversarias políticamente. Además estos discursos a través de estas televisiones dentro de las mezquitas o de los ulemas e imames legitimados por el poder oficial se insertan dentro de un papel de legitimación de los poderes religiosos y políticos de la institución monárquica y del Estado a fin de garantizar el control de este espacio en el que se crea la opinión pública religiosa ${ }^{75}$.

En el seno de la batalla por el control del simbolismo y del poder religioso, la Monarquía adoptaba una estrategia basada en la ruptura de la unidad de las filas de las fuerzas islámicas al convertir a una de ellas en una fuerza política aliada, como ocurrió con los salafistas, que sirvieron para deslegitimar al movimiento islamista Al Adl wa AL Ihsan, que era un adversario religioso y político. Algunas fuerzas islamistas marroquíes declaran entre sus objetivos políticos el apoyo a la Monarquía para evitar enfrentarse con ella, como es el caso de al Adala wa At-Tatnmiayah, que

75. Tozy. M (2008). Op. cit., p .21. 
está presidiendo el Gobierno en estos momentos ${ }^{76}$.

En general y como estrategia para enfrentar el reto del islamismo político, la Monarquía, a la que la Constitución otorga la legitimidad de representación religiosa en el país, sigue una política moderada con las fuerzas islamistas que no tienden a utilizar fuerza y no adoptan actitudes políticas y religiosas extremistas o avalan la violencia. La Monarquía pretende con esto evitar escenarios de confrontación no controlados, como ha sucedido en países como Egipto, Argelia, etc. En este momento, después del rumbo que ha tomado la primavera árabe, el país árabe con mayor estabilidad política es Marruecos ${ }^{77}$.

\section{Bibliografía}

Ben EIMustafá, U., (2008). Al Islamiuna al Maghāribah, (los islamistas marroquíes). Casablanca. Dar Tubkal. p. 11

Hroub, K., ( 2010) Political Islam: Context versus Ideology, London. Saqi.

Darif, M., (1996) "Al Maghreb fi taqatu3 at-turuq", (Marruecos en el cruce de los caminos). Casablanca, Maktabat- al-Najah al Jadida.

Darif, M., (2000) AL Islāmiuna al Maghāribah, I3tibarātun siasiah fi al feel al Islämi 1969-1999, (Los Islamistas Marroquíes: Consideraciones políticas en el

76. Macé. C, et Chevance, M (2016) "Maroc: les islamistes au centre du jeu". El periódico liberation.fr http://www.liberation.fr/planete/2016/ 10/06/maroc-les-islamistes-au-centre-dujeu_1520196

77. Es una de las excusas que adopta también el poder oficial en Marruecos para fortalecer su control del espacio público y de los valores religiosos frente a sus adversarios del islam político.
Acto Islámico 1969- 1999), Revista Ciencias Sociales.

Etienne, B., (2005) ¿Qué inquieta del Islam?, Barcelona, Edicions Bellaterra.

Gilles, K., (2000) Jihad, expansion et déclin de I islamisme, Paris., Gallimard.

Hilmi, M., (2005) Manhaju Ulamāe al Hadith wa as- sunnah fi Usul ad-dīne (Metodologia de los sabios del Islam en el hadith y as-sunnah en la teología islámica), Lebanon. Dār alkutub al ilmiah. Lebanon.

Hmimnat, S., (2009) "Al Islam al maghrebi fi al Jitāb al ideologie ar-rasmi", (El Islam Marroquí en el discurso ideológico oficial). En wijahat Nadar. № 39 -añol1.

Laurent, E. (2000) Le génie de la modération: réflexions sur les vérités de l'Islam, Paris. Plon.

Russel, B ( 2011) El Poder, un nuevo análisis social. traducción de Luis Echávarri. Barcelona.

Salgon, J.M. ( 2012) Dictionnaire de L'islamisme au Maghreb, L'Harmattan. .

Salīm, S. A.(2000) Al Mutazilah, Tārîj, Akāid, Firaq, Aalām (los muatazilies, Historia, doctrinas, grupos y personajes).institución Nawefal.

Sabeti , M (1993) As-salafiatu al wahabiah bel maghreb, (el salafismo wahhabi en Marruecos). Matbaat al maāref al jadidah, Rabat

Sobhi, M. A (1985) fi 3ilm_Al_Kalam ( En La Teologia islamica), Beirut. Dār anNahda al arabia

Tozy, M. (2008) Monarchie et Islam politique au Maroc, Paris. Presses de Science.

\section{Recursos electrónicos}

http://www.habous.gov.ma/fr/index.aspx . acceso: 12/9/2011 
http://www.aujourdhui.ma/imprime r/?rub=actualite\&ref=24056 acceso:10/10/2011

http://www.habous.gov.ma/index.php/ accueil/rubrique-france/academique/ islam-au-maroc/article-fr?id=83 acceso: 17/10/2011

http://www.arrabita.ma/moubachir/moubachir.aspx?L=37 .en árabe .acceso:

12/10/2011

http://islamyoon.islamonline.net/ servlet/Satellite?c=ArticleA_C\&ci $\mathrm{d}=1258445653033$ \&pagename $=$ Islamyoun\%2FIYALayout.en árabe. acceso en 25/4/2009

http://cort.as/-7Ycg )en árabe. acceso

$17 / 10 / 2011$

http://www.diwanalarab.com/spip.

php?article7576 en árabe: Acceso:

23//07/2010

http://www.aljamaa.net/

http://www.liberation.fr/plane-

te/2016/10/06/maroc-les-islamistes-aucentre-du-jeu_1520196 